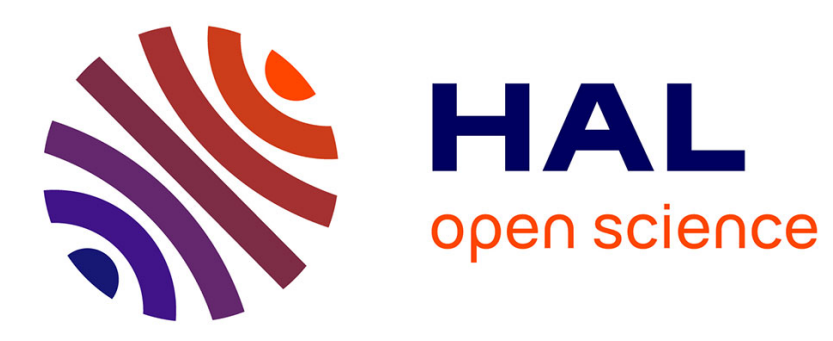

\title{
Controlling the Length of Cooperative Supramolecular Polymers with Chain Cappers
}

\author{
Gijs M. ter Huurne, Pongphak Chidchob, Augustin Long, Alexandre \\ Martinez, Anja R. A. Palmans, Ghislaine Vantomme
}

\section{- To cite this version:}

Gijs M. ter Huurne, Pongphak Chidchob, Augustin Long, Alexandre Martinez, Anja R. A. Palmans, et al. Controlling the Length of Cooperative Supramolecular Polymers with Chain Cappers. Chemistry - A European Journal, 2020, 26 (44), pp.9964-9970. 10.1002/chem.202001293 . hal-03180310

\author{
HAL Id: hal-03180310 \\ https://hal.science/hal-03180310
}

Submitted on 24 Mar 2021

HAL is a multi-disciplinary open access archive for the deposit and dissemination of scientific research documents, whether they are published or not. The documents may come from teaching and research institutions in France or abroad, or from public or private research centers.
L'archive ouverte pluridisciplinaire HAL, est destinée au dépôt et à la diffusion de documents scientifiques de niveau recherche, publiés ou non, émanant des établissements d'enseignement et de recherche français ou étrangers, des laboratoires publics ou privés. 


\title{
Controlling the Length of Cooperative Supramolecular Polymers with Chain Cappers
}

\author{
Gijs M. ter Huurne, ${ }^{[a]}$ Pongphak Chidchob, ${ }^{[a]}$ Augustin Long, ${ }^{[b]}$ Alexandre Martinez, ${ }^{[b]}$ \\ Anja R. A. Palmans, ${ }^{*[a]}$ and Ghislaine Vantomme ${ }^{*[a]}$
}

\begin{abstract}
The design and the characterization of supramolecular additives to control the chain length of benzene1,3,5-tricarboxamide (BTA) cooperative supramolecular polymers under thermodynamic equilibrium is unraveled. These additives act as chain cappers of supramolecular polymers and feature one face as reactive as the BTA discotic to interact strongly with the polymer end, whereas the other face is nonreactive and therefore impedes further polymerization. Such a design requires fine tuning of the conformational preorganization of the amides and the steric hindrance of
\end{abstract}

the motif. The chain cappers studied are monotopic derivatives of BTA, modified by partial $N$-methylation of the amides or by positioning of a bulky cyclotriveratrylene cage on one face of the BTA unit. This study not only clarifies the interplay between structural variations and supramolecular interactions, but it also highlights the necessity to combine orthogonal characterization methods, spectroscopy and light scattering, to elucidate the structures and compositions of supramolecular systems.

\section{Introduction}

Control over the nanoscale morphology of multicomponent systems is one of the key parameters to improve the performance of supramolecular polymeric materials. ${ }^{[1]}$ In fact, fine tuning of the noncovalent interactions connecting the supramolecular motifs is at the core of the material properties. ${ }^{[2]} \mathrm{Al}-$ though significant progress has been made in controlling the assembly pathway, structure and composition of supramolecular polymers, ${ }^{[3]}$ major challenges remain to control the chain length and the polymer sequence of supramolecular (co)polymers. The development of kinetically controlled supramolecular polymerization techniques, such as living supramolecular polymerization, has allowed significant progress in that direction. ${ }^{[3-[]}$ For systems under thermodynamic equilibrium, we recently reported on the various mechanisms directing the chain length in supramolecular (co)polymerizations. ${ }^{[4]}$ Next to the addition of good solvent, ${ }^{[5]}$ supramolecular additives can reduce the chain length by chain-capping the polymers or by stabilizing the monomers. In the latter, the additive is a competitor which depolymerizes the supramolecular chains without participating in the polymer sequence. The additive forms competitive, stable species that stabilize the monomers. ${ }^{[6]}$ In the former scenario, the additive is a chain capper, a component that interacts with the chain end, and inhibits further growth of the polymer chain. ${ }^{[7]}$ This chain-capping strategy has also been used to control dynamic libraries of cyclic and linear oligomers $^{[6 b, 8]}$ and to synthesize rotaxanes. ${ }^{[9]}$

In the field of isodesmic supramolecular polymerization, the noncovalent analogue of covalent step-growth polymerization, the concept of chain capper is well-established and its impact on the molecular weight has been studied in great detail. ${ }^{[7,10]}$ The design of a chain capper is straightforward because it is a monotopic derivative of the ditopic monomer. However, in cooperative supramolecular polymerization, the noncovalent analogue of covalent chain-growth polymerization, the design of a chain capper is far from trivial and only two examples have been formally reported in organic solvent. ${ }^{[11,12]}$ The challenge in designing an effective chain capper arises from the same molecular features that make the polymerization cooperative: a correlated reactivity of the two binding sites of the monomer. Hence, the monomer needs to be modified into a monofunctional derivative without affecting its association constant. To unravel the basic principles of chain-capping cooperative supramolecular polymers under thermodynamic control, a benzene-1,3,5-tricarboxamide monomer decorated with alkyl chains (a-BTA) is an ideal model system because of the simple design and the extensive knowledge acquired on its assembly properties. ${ }^{[13]}$ In addition, the assembly of benzene-1,3,5-tricarboxamides with aliphatic side chains is always under thermo- 
A

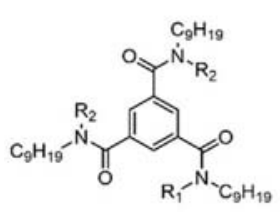

a-BTA : $R_{1}=R_{2}=H$

a-1Me-BTA $: R_{1}=M e ; R_{2}=H$

a-3Me-BTA : $R_{1}=R_{2}=M e$

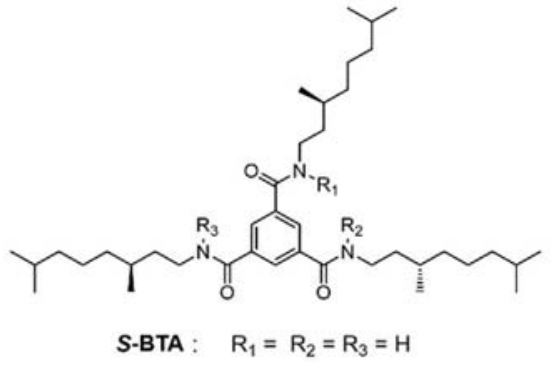

S-1Me-BTA : $\quad \mathrm{R}_{1}=\mathrm{Me} ; \mathrm{R}_{2}=\mathrm{R}_{3}=\mathrm{H}$

S-2Mo-BTA : $\quad \mathrm{R}_{1}=\mathrm{R}_{2}=\mathrm{Me} ; \mathrm{R}_{3}=\mathrm{H}$

S-3Me-BTA : $\quad \mathrm{R}_{1}=\mathrm{R}_{2}=\mathrm{R}_{3}=\mathrm{Me}$
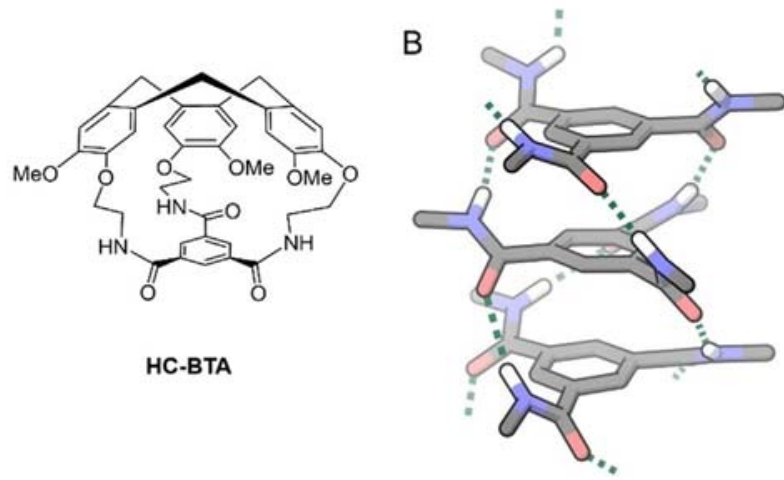

Scheme 1. (A) Chemical structures of the BTA derivatives studied in this work. (B) Schematic representation of the helical arrangement of the hydrogen bonds in the a-BTA supramolecular polymer.

dynamic control, and mixing two derivatives results in almost instantaneous co-assembly. ${ }^{[14]}$ This self-complementary a-BTA motif assembles cooperatively into one-dimensional aggregates stabilized by helically ordered, intermolecular hydrogenbond networks.

Here, we present our insights into how different designs of chain cappers affect the length of a-BTA polymers, and show which prerequisites need to be fulfilled to make the chain capper effective. To this end, a series of BTA-based molecules was synthesized and mixed with a-BTA polymers to investigate the influence of the amide conformation and the steric hindrance on the chain-capping effect. In order to gradually vary the structural similarity with the monomer a-BTA, we synthesized five monotopic BTA derivatives by $N$-methylation of three, ${ }^{[15]}$ two and one amides (chiral S-3Me-BTA, S-2Me-BTA and S-1Me-BTA and achiral a-1Me-BTA and a-3Me-BTA, Scheme 1). We opted for chiral, non-racemic methylated derivatives to permit the use of chiroptical spectroscopic techniques. In addition, one monotonic BTA derivative that comprises a bulky cyclotriveratrylene cage ${ }^{[16]}$ was also investigated (HC-BTA, Scheme 1). We examine in detail the influence of the chain capper on the structure of the supramolecular polymers using a combination of static light scattering (SLS), infrared (IR), UV and circular dichroism (CD) spectroscopy and density functional theory (DFT) calculations. The co-assembly experiments described here are conceptually similar to experiments reported in other studies. ${ }^{[11,17]}$

\section{Results and Discussion}

\section{Chemical design}

First, we investigate the prerequisites that need to be fulfilled to design the ideal chain capper. Taking inspiration from the design of chain cappers for isodesmic polymerization, a previous attempt to make a chain capper for a-BTA polymers was based on the monotopic $\mathrm{N}$-methylated 3Me-BTA. ${ }^{[15]}$ This monotopic derivative lacks the $\mathrm{N}-\mathrm{H}$ groups, which were alkylated into N-Me motifs. As a result, 3Me-BTA cannot act as a hydrogen bond donor but only as a hydrogen-bond acceptor through the carbonyls. Although 3Me-BTA was found to decrease the viscosity of a-BTA solution, it is not a chain capper of a-BTA polymers. ${ }^{[15]}$ When analyzed by DFT calculations, a different pre-organization of the amides of 3Me-BTA when compared to a-BTA was proposed to explain the unfavorable interaction between 3Me-BTA and a-BTA stacks. ${ }^{[15]}$ This example showed how the design of supramolecular (co)monomers is challenged by molecular pre-organization and in particular conformational preferences of the reactive groups. ${ }^{[15,18]}$ Thus, end-capping cooperative supramolecular polymers requires a subtle balance of the reactivity of the two faces of the chain capper, with one face preorganized to be as reactive as the monomer and the other face nonreactive to impede the supramolecular polymerization.

Based on the above results, we hypothesized that an efficient chain capper should have the following structural features: 1) a conformational preorganization of the amides similar to the monomer to ensure a strong binding with the polymer end, and 2) the presence of sterically hindered groups to mask the binding site for another monomer. Based on these design rules, we selected asymmetrically $N$-methylated BTA units (S-1Me-BTA and S-2Me-BTA) because of their structural similarity with a-BTA and the bulkiness of the methyl groups. 
Moreover, hemicryptophane-BTA (HC-BTA) ${ }^{[16]}$ previously developed for molecular recognition and catalysis, ${ }^{[19]}$ was selected for this study because of the preorganization of the amide units and the crowding of one of its faces ${ }^{[3]}$ with a bulky cyclotriveratrylene cage. The crystal structure of HC-BTA was previously solved ${ }^{[16]}$ and presents a conformational organization of the three amides oriented in the same direction to one another with a tilt angle from $5^{\circ}$ to $19^{\circ}$ with respect to the benzene ring, comparable to the amide conformations in a-BTA monomer $\left(12^{\circ}\right.$ tilt $) .{ }^{[13 \mathrm{~b}]}$ Here, we used (-)-M-HC-BTA for all experiments.

\section{Synthesis}

Chiral S-1Me-BTA, S-2Me-BTA and S-3Me-BTA were synthesized in one step in $14 \%, 19 \%$ and $53 \%$ yield, respectively, starting from S-BTA (see Supporting Information for details). Whereas chiral S-BTA was obtained as a white solid, all S-nMeBTAs (with $n=1,2$, and 3) were obtained as colorless isotropic liquids. HC-BTA was synthesized from a cyclotriveratrylene derivative and benzenetricarbonyl trichloride in $5 \%$ yield and was obtained as a white solid. ${ }^{[16]}$

\section{Homoaggregation of S-nMe-BTAs}

S-1Me-BTA, S-2Me-BTA and HC-BTA exhibit self-complementary hydrogen-bond donor/acceptor units in their structures, so we first investigated their ability to assemble into supramolecular homoaggregates. Previous studies showed that when BTAs polymerize into one-dimensional aggregates stabilized by a helically ordered, intermolecular hydrogen-bond network, IR spectra show an $\mathrm{N}-\mathrm{H}$ stretch at about $\approx 3240 \mathrm{~cm}^{-1}$, the $\mathrm{C}=\mathrm{O}$ amide I at $\approx 1640 \mathrm{~cm}^{-1}$ and the amide II at $\approx 1560 \mathrm{~cm}^{-1}$. ${ }^{[13 \mathrm{~b}]}$ In contrast, vibrations for the $\mathrm{NH}$ stretch at $\approx 3306 \mathrm{~cm}^{-1}$ and an amide II vibration at $\approx 1539 \mathrm{~cm}^{-1}$ are typical for lateral hydrogen-bond networks. ${ }^{[13 b]}$ The IR spectra in the bulk state of $S$ 1Me-BTA and S-2Me-BTA reveal the $\mathrm{N}-\mathrm{H}$ stretch at $\approx 3320 \mathrm{~cm}^{-1}$, the $\mathrm{C}=\mathrm{O}$ amide I vibrational mode at $\approx 1635 \mathrm{~cm}^{-1}$ and the amide II vibrational mode at $\approx 1539 \mathrm{~cm}^{-1}$ (Figure S1). This indicates that these compounds do not form helically-ordered intermolecular hydrogen bonds in the bulk. In dilute solution of nonpolar solvent (methylcyclohexane (MCH), $1 \mathrm{~mm}), \mathrm{S}-1 \mathrm{Me}-\mathrm{BTA}$ and S-2Me-BTA exhibit the $\mathrm{N}-\mathrm{H}$ stretching vibration at $\approx 3300 \mathrm{~cm}^{-1}$ and $3450 \mathrm{~cm}^{-1}$, three $\mathrm{C}=\mathrm{O}$ stretch I vibrations around $1674 \mathrm{~cm}^{-1}$ (free $\mathrm{C}=0$ ), $1627 \mathrm{~cm}^{-1}$ and $1650 \mathrm{~cm}^{-1}$ (bonded $\mathrm{C}=\mathrm{O}$ ) and the amide II vibration at $\approx 1539 \mathrm{~cm}^{-1}$ (Figure 1). These data point to the coexistence of free amides and intermolecular lateral hydrogen-bonded amides. IR measurements of HC-BTA show the characteristics of the monomeric state both in bulk and in toluene, with vibrations of the $\mathrm{N}-\mathrm{H}$ stretch at $3440 \mathrm{~cm}^{-1}$ (free $\mathrm{N}-\mathrm{H}$ ), the $\mathrm{C}=\mathrm{O}$ stretch at about $1665 \mathrm{~cm}^{-1}$ and $1520 \mathrm{~cm}^{-1}$ (Figure 1). These IR signals are similar to S-BTA in tetrachloromethane. ${ }^{[20]}$ Toluene was chosen here because of the poor solubility of HC-BTA in millimolar concentration in $\mathrm{MCH}$. In addition, the chiroptical properties of these solutions were investigated by CD and UV/ Vis spectroscopy. The diluted solutions of S-nMe-BTA in $\mathrm{MCH}$

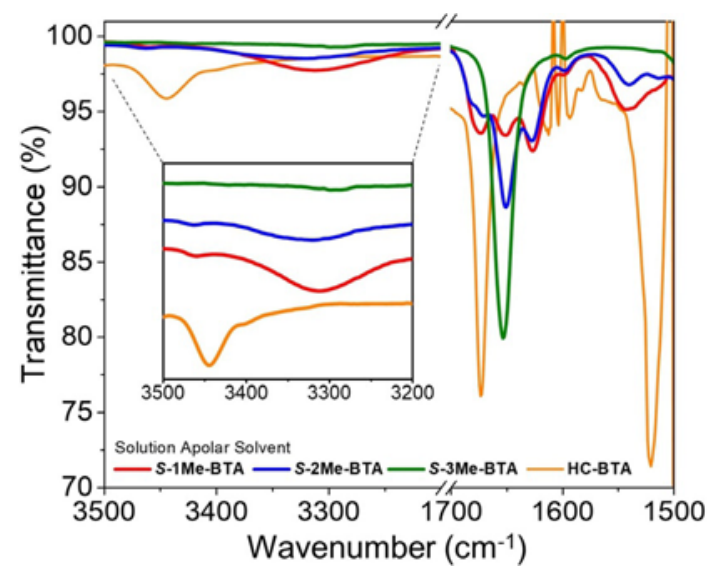

Figure 1. FTIR spectra of $S$-nMe-BTA ( $n=1,2$ or 3 ) in $\mathrm{MCH}\left(T=20^{\circ} \mathrm{C}\right.$, $c=1 \mathrm{~mm})$ and $\mathrm{HC}$-BTA in toluene $\left(T=20^{\circ} \mathrm{C}, \mathrm{C}=1 \mathrm{~mm}\right)$.

are CD silent (Figure S2), which corroborate the IR data that no $\mathrm{C}_{3}$-symmetrical helical aggregates are formed. For HC-BTA, a $10 \mu \mathrm{M}$ solution in $\mathrm{MCH}$ displays a $\mathrm{CD}$ pattern that is similar to the spectrum previously reported in acetonitrile. ${ }^{[16]}$ However, the $C D$ intensity does not change over temperature (Figure S3). These results also confirm that HC-BTA does not aggregate in diluted solution.

\section{Co-assembly studied by spectroscopy}

We then performed mixing experiments between a-BTA and $S$ nMe-BTA ( $n=1,2$ or 3 ) or HC-BTA at different concentrations in nonpolar solvent, and analyzed the solutions by IR, UV and CD spectroscopy. The concentration of a-BTA was fixed and the quantity of additives S-nMe-BTA was gradually increased in the mixtures from 0 to $25 \mathrm{~mol} \%$. Surprisingly, in CD spectroscopy, only a weak chiroptical signal was detected in the various mixtures of $50 \mu \mathrm{M}$ a-BTA containing S-nMe-BTA in MCH (Figure S4). This result indicates that the chiral additive $S$ nMe-BTA is not able to bias the helical preference of the polymers formed by achiral a-BTA monomers. This is in sharp contrast to the full bias of helicity observed when mixing $5 \mathrm{~mol} \%$ of the chiral S-BTA with a-BTA stacks. ${ }^{[14]}$ Variable-temperature UV experiments were carried out on these a-BTA/S-nMe-BTA mixtures (Figure 2). All UV cooling curves overlap and have a non-sigmoidal shape indicating an assembly via a cooperative mechanism as observed for a-BTA homopolymers. Moreover, we observed no change in the temperature at which aggregation starts (the elongation temperature, $T_{\mathrm{e}}$ ) upon the addition of S-nMe-BTA. This suggests that the thermal stability of the aBTA polymers is not affected by the presence of S-nMe-BTA. These results point to either an absence of interactions between a-BTA polymers and S-nMe-BTA (self-sorting) or to a chain-capper role of S-nMe-BTA for a-BTA stacks. ${ }^{[4]}$ This is in contrast to two other scenarios: 1) an increase in $T_{\mathrm{e}}$ is expected if S-nMe-BTA intercalates into a-BTA stacks because the total concentration of BTAs present in supramolecular polymers increases, ${ }^{[21]}$ or 2) a decrease of $T_{\mathrm{e}}$ is expected when S-nMe-BTA interacts with a-BTA monomers by forming short stable side 


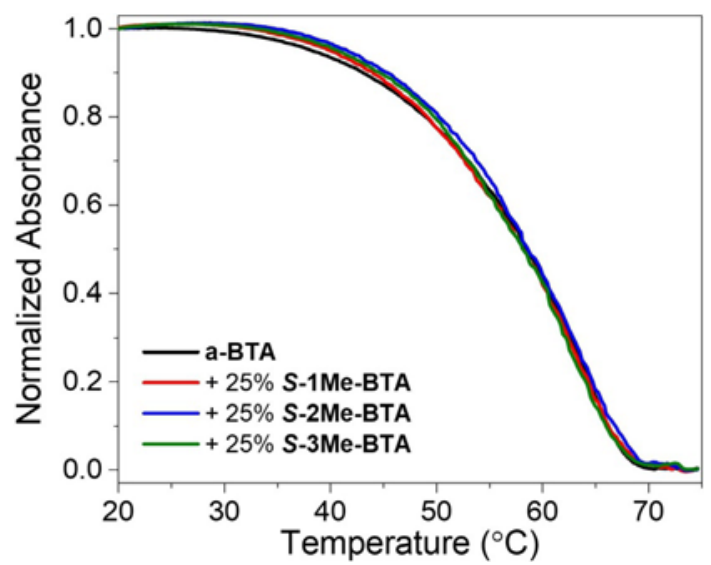

Figure 2. Temperature-dependent UV spectra of solutions of $50 \mu \mathrm{M}$ a-BTA with addition of $25 \mathrm{~mol} \%$ of S-nMe-BTA probed at $217 \mathrm{~nm}$ in $\mathrm{MCH}$ (cooling rate $=2{ }^{\circ}\left(\mathrm{min}^{-1}\right)$.

species in a competitive pathway, which effectively decreases the concentration of BTAs present in the supramolecular polymers. ${ }^{[6 c]}$ For the analysis of HC-BTA, UV/CD spectroscopy could not be performed for a-BTA/HC-BTA solutions in toluene because of the overlap between the solvent absorption and the maximum absorption of BTA monomers.

The IR spectroscopy analyses were performed on $1 \mathrm{~mm}$ aBTA solutions in $\mathrm{MCH}$, with the addition of $100 \mathrm{~mol} \%$ and $25 \mathrm{~mol} \%$ of S-nMe-BTA (Figure $3 \mathrm{~A}$ and Figure S5). For the mixtures of S-3Me-BTA and a-BTA, no clear proof of interaction is visible because of the overlap between the stretching vibrations of free $\mathrm{C}=\mathrm{O}$ of the tertiary amide in S-3Me-BTA and bonded $\mathrm{C}=\mathrm{O}$ in a-BTA. In contrast, the mixtures of $\mathrm{S}-1 \mathrm{Me-BTA} /$ a-BTA and S-2Me-BTA/a-BTA show a shift in the ratio between free and bonded $\mathrm{C}=\mathrm{O}$ stretch vibrations (at $1647 \mathrm{~cm}^{-1}$ / $1630 \mathrm{~cm}^{-1}$ ), indicating the preference of bonded $C=0$, which characterizes the presence of helical polymers. These changes are, however, rather small so that unambiguous conclusions on the nature of the co-assembly in mixtures of $S-1 \mathrm{Me}-\mathrm{BTA} / \mathrm{a}-$ BTA and S-2Me-BTA/a-BTA cannot be drawn. When $10 \mathrm{~mol} \%$ of HC-BTA was added into $5 \mathrm{~mm}$ toluene solution of a-BTA, the IR spectrum obtained for the mixtures of the solutions is very close to the linear combinations of the separate components (Figure $3 \mathrm{~B}$ ). Therefore, we cannot conclude whether the mixtures of HC-BTA and a-BTA assemble into a-BTA homopolymers with free HC-BTA or if an interaction between the two is present. And further analysis with light scattering techniques was conducted.

\section{Coassembly studied by light scattering}

To further understand the interactions between the different additives and a-BTA, the weight-average length of the supramolecular polymers as a function of the addition of S-nMeBTA and HC-BTA was measured by static light scattering (SLS) experiments (Figure 4 and Figure S6). The scattering curves were fitted to a cylinder model with a fixed radius of $6 \mathrm{~nm}$ (radius obtained from SAXS measurements). ${ }^{[6]]}$ Upon addition of S-3Me-BTA to a-BTA, the changes in a-BTA polymer length
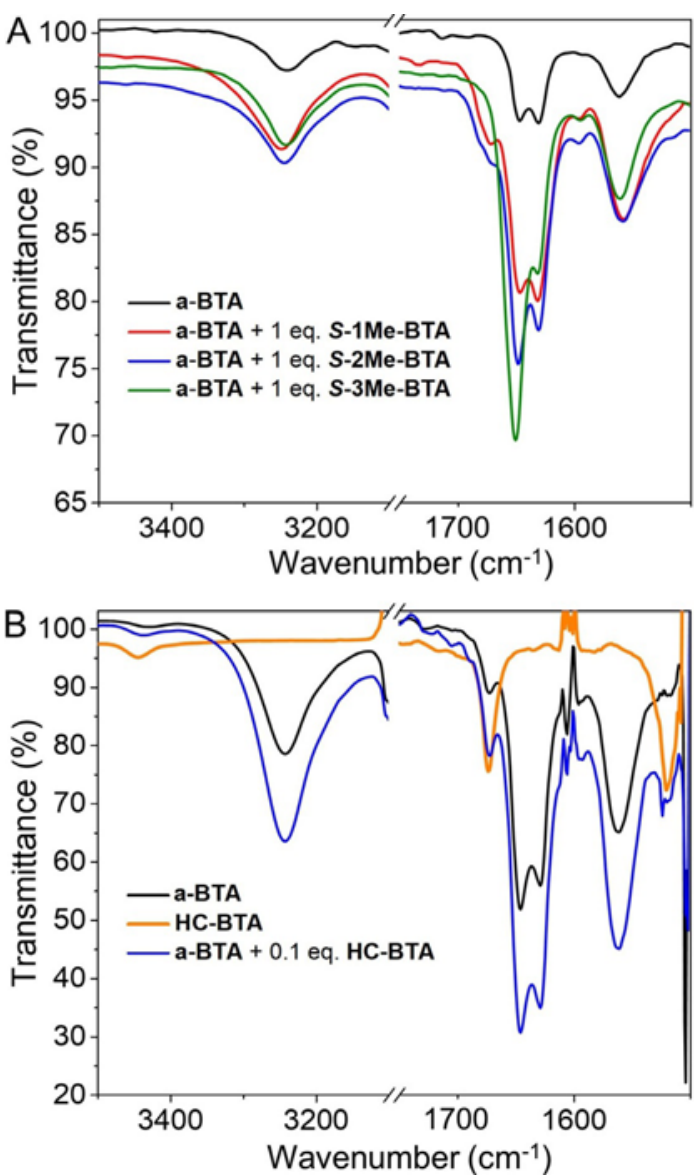

Figure 3. A) FTIR spectra of $1 \mathrm{~mm} M C H$ solutions of a-BTA containing an additional $100 \mathrm{~mol} \%$ ( 1 equiv.) of S-nMe-BTA ( $n=1,2$ and 3 ) at $20^{\circ} \mathrm{C}$. B) FTIR spectra of $5 \mathrm{~mm}$ toluene solutions of a-BTA, HC-BTA and a-BTA with addition of $10 \mathrm{~mol} \%$ (0.1 equiv.) of HC-BTA at $20^{\circ} \mathrm{C}$.

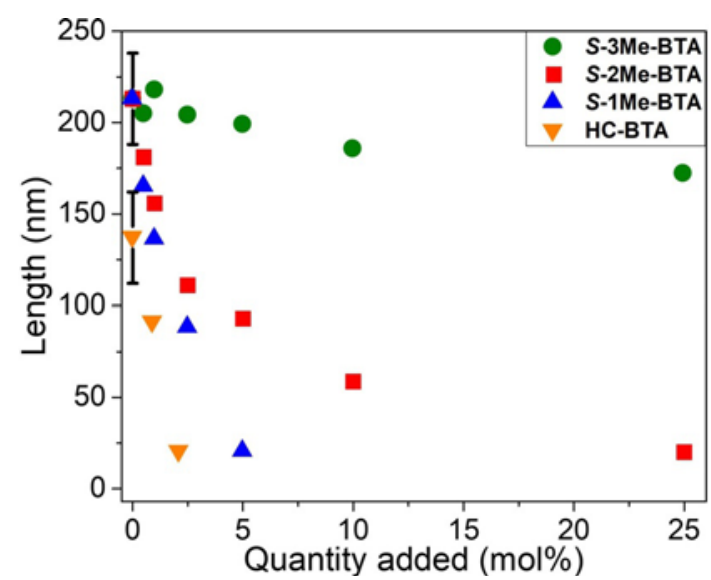

Figure 4. Measured weight-average length of the supramolecular polymer as function of S-nMe-BTA ( $n=1,2$, or 3 ) added (blue, red, and green traces, respectively) determined by SLS at $C_{\mathrm{a}-\mathrm{BTA}}=0.5 \mathrm{~mm}$ in $\mathrm{MCH}$ and of HC-BTA added (orange trace) at $C_{\mathrm{a}-\mathrm{BTA}}=5 \mathrm{~mm}$ in toluene at $20^{\circ} \mathrm{C}$.

are negligible. This result confirms that S-3Me-BTA does not have a high affinity for the polymer-ends (Figure 4, green dots). ${ }^{[15]}$ However, when small amounts of S-1Me-BTA, S-2MeBTA or HC-BTA are added to the solutions of a-BTA stacks, a 
strong decrease in polymer length is observed (Figure 4, blue, red and orange dots, respectively). Recent theoretical modelling developed to elucidate the role of an additive on the length of supramolecular polymers reveals that this sharp decrease of the polymer length with small amount of additive is indicative for a chain-capping effect. ${ }^{[4]}$ Therefore, we conclude that S-1Me-BTA, S-2Me-BTA and HC-BTA act as chain cappers of a-BTA stacks. The sharpest reduction in chain length is obtained with the addition of HC-BTA. However, no comparison can be drawn with the efficiency of S-nMe-BTA because the measurements are performed in a more polar solvent at higher concentration, which has a strong impact on the polymer length. ${ }^{[4]}$ Overall, this result shows that the chain capping is more efficient when the molecular structures of the chain capper and the monomer are similar.

\section{Computational characterization of S-nMe-BTA}

The question remains why S-3Me-BTA does not act as a chain capper while $S$-1Me-BTA does. To understand the origin of this result, density functional theory (DFT) calculations were performed on nMe-BTA bearing short methyl side chains to reduce computational costs. For $3 \mathrm{Me}-\mathrm{BTA}$, it was previously reported that the equilibrium geometry is characterized by an antiparallel arrangement of the amide moieties with an aver-

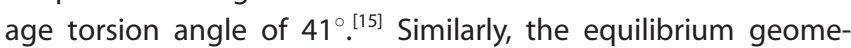
tries obtained for 1Me-BTA and 2Me-BTA also display an antiparallel arrangement of the amide moieties with a torsion angle of about $20^{\circ}$ for the $\mathrm{NH}$ amides and about $40^{\circ}$ for the NMe amides (Figure 5 and Figures S7 and S8). For nMe-BTA to interact with a-BTA stacks, a similar organization of the amides is necessary. We hypothesized that the difference in the energy barrier for the conformational inversion of amides $\mathrm{NH}$ and NMe would explain the difference in chain-capping properties between S-1Me-BTA and S-3Me-BTA. The energies profiles were obtained by scanning the torsional potential surface in $10^{\circ}$ increments for the $\mathrm{C}_{\text {arom }}-\mathrm{C}_{\text {arom }}-\mathrm{C}_{\mathrm{CO}}-\mathrm{O}$ dihedral angle of nMeBTA and optimizing the equilibrium geometries (Figure 5). The results show that the energy barrier to rotate the $C_{\text {arom }}-C_{\text {arom }}{ }^{-}$ $\mathrm{C}_{\mathrm{CO}} \mathrm{O}$ dihedral angle of a NH amide of 1Me-BTA is about $0.2 \mathrm{kcal} \mathrm{mol}^{-1}$ (Figure 5, top panel), in agreement with previously reported values for BTA. ${ }^{[13 b]}$ In contrast, for 3Me-BTA, the rotation of the NMe amide goes through an energy barrier of $4.2 \mathrm{kcal} \mathrm{mol}^{-1}$ (Figure 5, bottom panel). This energy difference is attributed to the steric repulsion generated by the $\mathrm{N}$-methyl group coming into the plane of the benzene ring. Thus, the difference in binding affinity between S-1Me-BTA and S-3MeBTA with a-BTA stacks can be attributed to the less energetically demanding pre-organization of the amide moieties for $S$ 1Me-BTA compared to S-3Me-BTA.

\section{Coassembly studied by sergeant and soldiers experiments}

To corroborate the chain-capping effect, a final experiment was performed by using the well-known sergeant and soldiers principle. ${ }^{[22]}$ Herein, a small amount of chiral S-BTA biases the helical preference of a-BTA supramolecular polymers. In this case, we add the achiral chain capper a-1Me-BTA to investigate its effect on the chiroptical properties of the sergeants/ soldiers S-BTA/a-BTA mixture (Scheme 1).

A 5/95 mixture of chiral S-BTA sergeant and achiral a-BTA soldiers was prepared at a total concentration of $50 \mu \mathrm{M}$ in $\mathrm{MCH}$. The sergeant S-BTA intercalates into a-BTA stacks and successfully biases the helical preference of a-BTA stacks,<smiles>CNC(=O)c1cc(C(=O)NC(C)(C)C)cc(C(=O)N(C)C)c1</smiles>

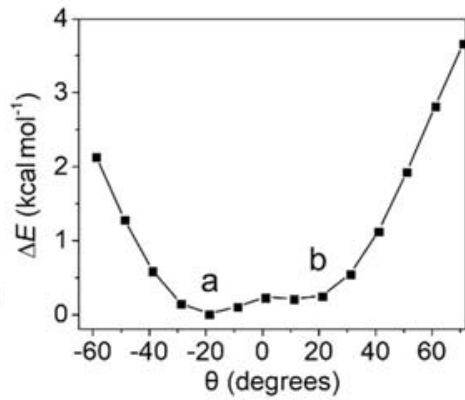<smiles>CN(C)C(=O)c1cc(C(=O)N(C)C)cc(C(=O)N(C)C)c1</smiles>
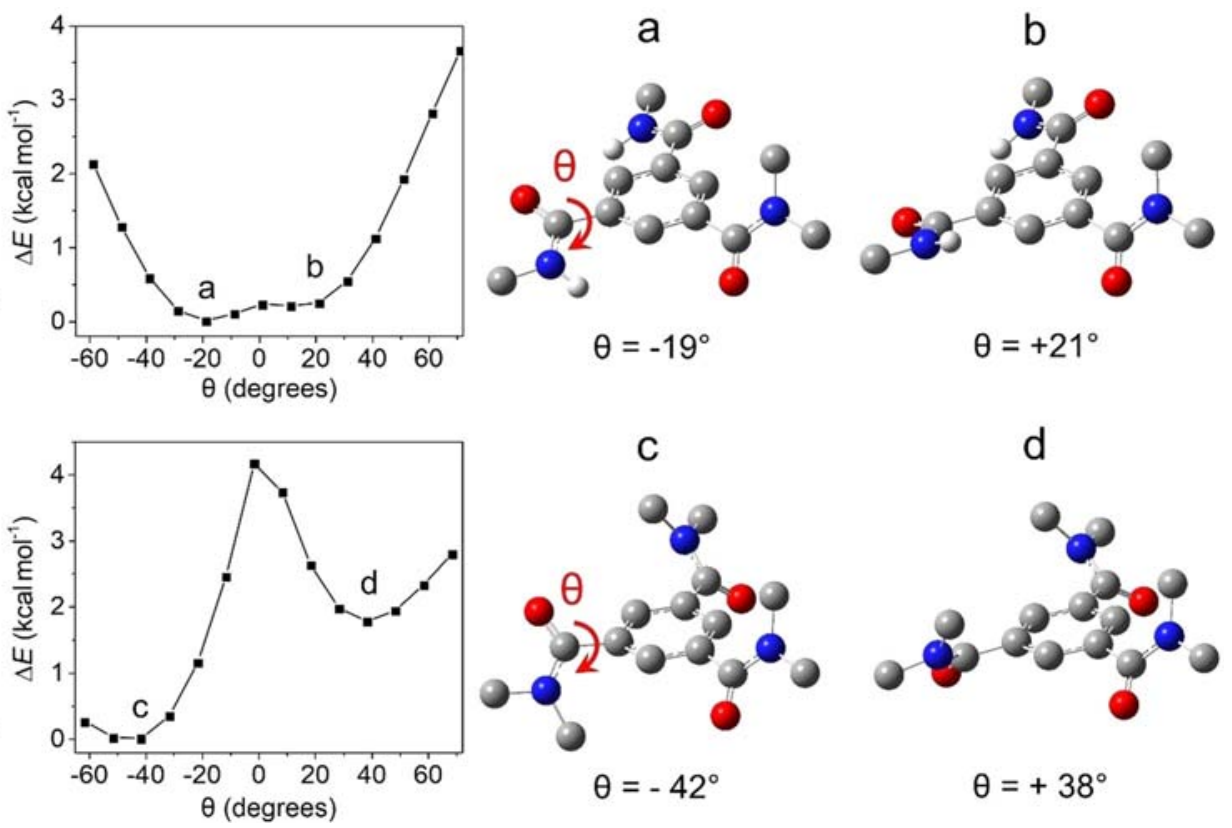

Figure 5. (Left) Potential energy profiles of 1 Me-BTA and 3 Me-BTA as a function of the $C_{\text {arom }}-C_{\text {arom }}-C_{\mathrm{co}_{0}}-\mathrm{O}$ dihedral angle $\theta$ obtained by single point calculations determined by DFT calculations at the PBE/ $6-311 \mathrm{G}+(\mathrm{d}, \mathrm{p}$ ) level of theory. (Right) Optimized structures of 1Me-BTA ( $a$ and $b$ ) and 3 Me-BTA (c and d) highlighted in the energy profiles. The hydrogen atoms of the carbons were omitted for clarity. 
giving a maximum $C D$ signal of about $-50 \mathrm{Lmol}^{-1} \mathrm{~cm}^{-1}$. Upon addition of achiral chain capper a-1Me-BTA to the sergeant/ soldiers mixtures, a pronounced decrease of the $C D$ signal is observed (Figure 6A, Figure S9). Half of the original CD intensity was reached at about 20 mol\% (0.2 equiv.) of a-1Me-BTA added. This decrease was not observed when a-3Me-BTA was added to the sergeant/soldiers mixtures, ${ }^{[15]}$ indicating that there is a definite interaction between a-1Me-BTA and BTAbased aggregates.

An explanation of the observed reduction in the $C D$ effect when adding a-1Me-BTA is as follows: when a-1Me-BTA acts as a chain capper in the sergeant/soldiers mixtures, the stack length decreases and as a result the number of polymer stacks increases. In this situation, new a-BTA stacks can form in both $P$ and $M$ helical sense, leading to a decrease in the net $M$ helicity (Figure $6 \mathrm{~B}$ ). During this experiment, the fraction of monomers aggregated stays approximately the same, as can be seen by the similar $T_{\mathrm{e}}$ of the UV melting curves over addition of chain capper (Figure S10). Interestingly, although a-1MeBTA acts as a chain capper for a-BTA polymers, S-1Me-BTA is not capable of biasing the helical sense of a-BTA polymers (see above). We speculate that S-1Me-BTA chain capper is a weak sergeant and that the ditopic intercalation of a sergeant into a polymer chain is necessary to effectively bias the helicity of a polymer.

A

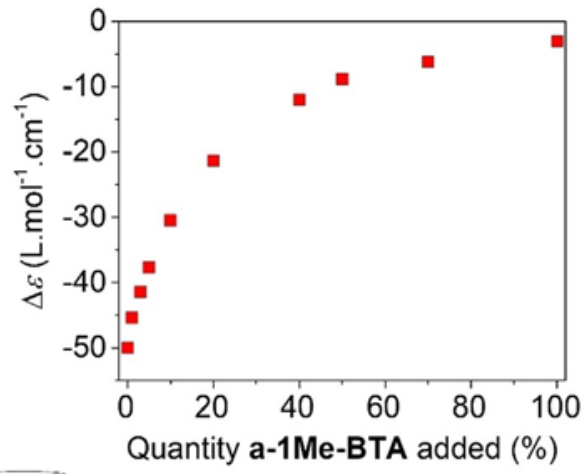

B

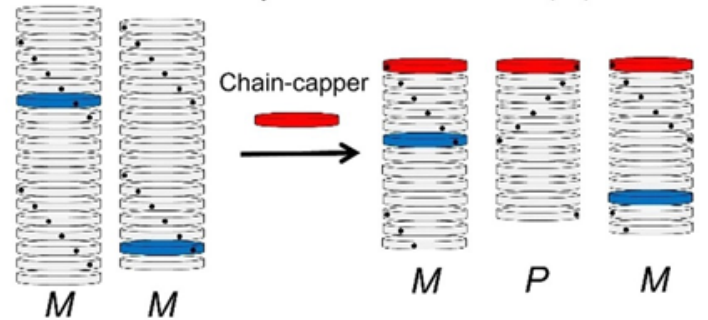

Figure 6. A) Maximum CD intensity of $50 \mu \mathrm{M}$ a-BTA/S-BTA $95 / 5$ solution over addition of $1 \mathrm{~mm}$ achiral a-1Me-BTA (mol\%) in MCH at $20^{\circ} \mathrm{C}$. B) Scheme of the sergeant (blue disks) and soldiers (grey disks) experiments with addition of chain capper (red disks).

\section{Conclusions}

In conclusion, we reported the synthesis and characterization of supramolecular additives designed to end-cap BTA cooperative supramolecular polymers under thermodynamic control. These supramolecular additives are monotopic derivatives of
a-BTA, modified by $\mathrm{N}$-methylation of two or one amides or decorated with a hemicryptophane unit to crowd one face of the monomer. The supramolecular copolymerization between a-BTA monomers and the chain cappers S-nMe-BTA ( $n=1$ and 2) or HC-BTA were analyzed by IR, UV, and CD spectroscopy as well as static light scattering in nonpolar solvent. The results show that the design of a discotic chain capper requires a fine balance between reactivity, to get one face of the chain capper as reactive as the monomer, and steric hindrance, so the other face hampers the polymerization. These findings also prove that the use of several characterization methods in concert is crucial to understand supramolecular systems. These results contribute to the general understanding of the interactions driving the structures of supramolecular polymers.

\section{Experimental Section}

\section{Methods}

The solutions for the experiments of CD, UV/Vis, FTIR and SLS were prepared as followed. The desired amount of compounds was weighed into an aluminium pan by using a microbalance and transferred into a $25 \mathrm{~mL}$ volumetric flask. Then the flask was filled $3 / 4$ full with $\mathrm{MCH}$ and sonicated at $40^{\circ} \mathrm{C}$ for $1 \mathrm{~h}$. After cooling the flask to $20^{\circ} \mathrm{C}$, the liquid meniscus was adjusted to the graduation line of the volumetric flask with $\mathrm{MCH}$. Solutions were stored in the dark at room temperature and used within two weeks after preparation.

For the "Sergeant-and-Soldiers" experiments, stocks solution of aBTA, S-BTA and a-1Me-BTA were prepared as described above. The $50 \mu \mathrm{m}$ stock solutions of a-BTA and S-BTA were mixed in a volume ratio $0.95 / 0.05$ for soldier/sergeant a-BTA/S-BTA. Then, a $1 \mathrm{~mm}$ stock solution of a-1Me-BTA was gradually added to the soldier/sergeant solution.
[1] a) T. Aida, E. W. Meijer, S. I. Stupp, Science 2012, 335, 813; b) G. M. Whitesides, Small 2005, 1, 172-179.

[2] a) J.-M. Lehn, Angew. Chem. Int. Ed. 2015, 54, 3276-3289; Angew. Chem. 2015, 127, 3326-3340; b) H. Liu, J. Xu, Y. Li, Y. Li, Acc. Chem. Res. 2010, 
43, $1496-1508$; c) J. Park, Q. Jiang, D. Feng, L. Mao, H.-C. Zhou, J. Am. Chem. Soc. 2016, 138, 3518-3525.

[3] a) T. F. A. De Greef, M. M. J. Smulders, M. Wolffs, A. P. H. J. Schenning, R. P. Sijbesma, E. W. Meijer, Chem. Rev. 2009, 109, 5687-5754; b) L. Yang, X. Tan, Z. Wang, X. Zhang, Chem. Rev. 2015, 115, 7196-7239; c) P. Besenius, J. Polym. Sci. Part A 2017, 55, 34-78; d) C. Rest, R. Kandanelli, G. Fernández, Chem. Soc. Rev. 2015, 44, 2543-2572; e) M. Raynal, F. Portier, P. W. N. M. van Leeuwen, L. Bouteiller, J. Am. Chem. Soc. 2013 135, 17687-17690; f) A. Das, G. Vantomme, A. J. Markvoort, H. M. M. ten Eikelder, M. Garcia-Iglesias, A. R. A. Palmans, E. W. Meijer, J. Am. Chem. Soc. 2017, 139, 7036-7044; g) J. B. Gilroy, T. Gädt, G. R. Whittell, L. Chabanne, J. M. Mitchels, R. M. Richardson, M. A. Winnik, I. Manners, Nat Chem. 2010, 2, 566-570; h) J. Kang, D. Miyajima, T. Mori, Y. Inoue, Y. Itoh, T. Aida, Science 2015, 347, 646; i) S. Ogi, K. Sugiyasu, S. Manna, S. Samitsu, M. Takeuchi, Nat. Chem. 2014, 6, 188-195.

[4] E. Weyandt, M. F. J. Mabesoone, L. N. J. De Windt, E. W. Meijer, A. R. A. Palmans, G. Vantomme, Org. Mater. 2020, 2, 129-142.

[5] a) P. A. Korevaar, C. Schaefer, T. F. A. de Greef, E. W. Meijer, J. Am. Chem. Soc. 2012, 134, 13482-13491; b) K. Venkata Rao, D. Miyajima, A. Nihonyanagi, T. Aida, Nat. Chem. 2017, 9, 1133-1139.

[6] a) F. Helmich, C. C. Lee, M. M. L. Nieuwenhuizen, J. C. Gielen, P. C. M. Christianen, A. Larsen, G. Fytas, P. E. L. G. Leclère, A. P. H. J. Schenning, E. W. Meijer, Angew. Chem. Int. Ed. 2010, 49, 3939-3942; Angew. Chem. 2010, 122, 4031-4034; b) M. J. Mayoral, D. Serrano-Molina, J. CamachoGarcía, E. Magdalena-Estirado, M. Blanco-Lomas, E. Fadaei, D. GonzálezRodríguez, Chem. Sci. 2018, 9, 7809-7821; c) G. Vantomme, G. M. ter Huurne, C. Kulkarni, H. M. M. ten Eikelder, A. J. Markvoort, A. R. A. Palmans, E. W. Meijer, J. Am. Chem. Soc. 2019, 141, 18278-18285.

[7] R. P. Sijbesma, F. H. Beijer, L. Brunsveld, B. J. B. Folmer, J. H. K. K. Hirschberg, R. F. M. Lange, J. K. L. Lowe, E. W. Meijer, Science 1997, 278, 1601

[8] M. Ciaccia, I. Tosi, L. Baldini, R. Cacciapaglia, L. Mandolini, S. Di Stefano, C. A. Hunter, Chem. Sci. 2015, 6, 144-151.

[9] W. R. Dichtel, O. Š. Miljanić, J. M. Spruell, J. R. Heath, J. F. Stoddart, J. Am. Chem. Soc. 2006, 128, 10388-10390.

[10] a) U. Michelsen, C. A. Hunter, Angew. Chem. Int. Ed. 2000, 39, 764-767; Angew. Chem. 2000, 112, 780-783; b) P. Terech, A. Coutin, Langmuir 1999, 15, 5513-5525; c) S. Yagai, T. Iwashima, T. Karatsu, A. Kitamura, Chem. Commun. 2004, 1114-1115.
[11] a) F. Lortie, S. Boileau, L. Bouteiller, C. Chassenieux, F. Lauprêtre, Macromolecules 2005, 38, 5283-5287; b) W. Knoben, N. A. M. Besseling, M. A. Cohen Stuart, J. Chem. Phys. 2007, 126, 024907; c) W. Knoben, N. A. M Besseling, M. A. Cohen Stuart, Macromolecules 2006, 39, 2643-2653 d) W. Knoben, N. A. M. Besseling, L. Bouteiller, M. A. Cohen Stuart, Phys. Chem. Chem. Phys. 2005, 7, 2390-2398; e) T. Pinault, B. Andrioletti, L. Bouteiller, Beilstein J. Org. Chem. 2010, 6, 869-875.

[12] E. Weyandt, G. M. ter Huurne, G. Vantomme, A. J. Markvoort, A. R. A. Palmans, E. W. Meijer, J. Am. Chem. Soc. 2020, 142, 6295-6303.

[13] a) S. Cantekin, T. F. A. de Greef, A. R. A. Palmans, Chem. Soc. Rev. 2012 41, 6125-6137; b) P. J. M. Stals, J. C. Everts, R. de Bruijn, I. A. W. Filot, M. M. J. Smulders, R. Martín-Rapún, E. A. Pidko, T. F. A. de Greef, A. R. A. Palmans, E. W. Meijer, Chem. Eur. J. 2010, 16, 810-821.

[14] M. M. J. Smulders, A. P. H. J. Schenning, E. W. Meijer, J. Am. Chem. Soc. 2008, 130, 606-611.

[15] M. M. J. Smulders, M. M. L. Nieuwenhuizen, M. Grossman, I. A. W. Filot, C. C. Lee, T. F. A. de Greef, A. P. H. J. Schenning, A. R. A. Palmans, E. W. Meijer, Macromolecules 2011, 44, 6581-6587.

[16] A. Long, M. Jean, M. Albalat, N. Vanthuyne, M. Giorgi, M. Górecki, J.-P. Dutasta, A. Martinez, Chirality 2019, 31, 910-916.

[17] a) F. García, L. Sánchez, J. Am. Chem. Soc. 2012, 134, 734-742; b) A. Desmarchelier, X. Caumes, M. Raynal, A. Vidal-Ferran, P. W. N. M. van Leeuwen, L. Bouteiller, J. Am. Chem. Soc. 2016, 138, 4908-4916.

[18] I. A. W. Filot, A. R. A. Palmans, P. A. J. Hilbers, R. A. van Santen, E. A. Pidko, T. F. A. de Greef, J. Phys. Chem. B 2010, 114, 13667-13674.

[19] D. G. Rivera, L. A. Wessjohann, J. Am. Chem. Soc. 2006, 128, 7122-7123.

[20] L. Brunsveld, A.P. H. J. Schenning, M. A. C. Broeren, H. M. Janssen, J. A. J. M. Vekemans, E. W. Meijer, Chem. Lett. 2000, 29, 292-293.

[21] L. N. J. de Windt, C. Kulkarni, H. M. M. ten Eikelder, A. J. Markvoort, E. W. Meijer, A. R. A. Palmans, Macromolecules 2019, 52, 7430-7438.

[22] M. M. Green, M. P. Reidy, R. D. Johnson, G. Darling, D. J. O'Leary, G. Willson. J. Am. Chem. Soc. 1989. 111. 6452-6454. 